\title{
Integrated Technology of University Students' Sports Selection and Orientation in Physical Education Specializations Tailored to Individual Characteristics
}

\author{
Victor N. Kovaleva, Svetlana K. Ryabinina ${ }^{a}$, \\ Mikhail D. Kudryavtseva,b,c and Sergey L. Sadyrina* \\ ${ }^{a}$ Siberian Federal University \\ Krasnoyarsk, Russian Federation \\ ${ }^{b}$ Siberian Law Institute of the Ministry of Internal \\ Affairs of the Russian Federation \\ Krasnoyarsk, Russian Federation \\ 'Siberian State University of Science and Technology \\ Krasnoyarsk, Russian Federation
}

Received 30.10.2020, received in revised form 24.12.2020, accepted 02.02.2021

\begin{abstract}
The article analyzes student sport, which is a reserve of high-performance sport, on the one hand, and a powerful factor in health preservation and socialization of future specialists and active members of society, on the other hand. The article discusses sports selection and orientation in the context of sportization of orientation of university physical education towards preservation of students' health, creation of health-forming educational space to ensure the development of health-forming values that result in the improvement of students' health and physical condition.

The aim of the study is to develop, apply and evaluate the effectiveness of the integrated technology of students' sports selection and orientation towards university physical education specializations tailored to students' individual characteristics.

The general scientific research methodology is presented by a systematic approach to determining a person's individual characteristics in the unity and interrelation of biological, social and psychological components, their influence on choice and success in certain activities, and their impact on health. Methods of scientific analysis, observation, experiment, empirical methods of psychological diagnostics, psychophysiological methods, statistical and mathematical methods were used. The study was conducted from January, 2016 to September, 2020. It involved 327 people: athletes from the DYUSSHOR (children and youth sports school of the Olympic reserve) of the Krasnoyarsk Krai, adult athletes, and the 1st, 2nd and 3rd year students of the schools of Siberian Federal University from educational specializations in basketball, aerobics, and rock climbing.
\end{abstract}

\footnotetext{
(C) Siberian Federal University. All rights reserved

* Corresponding author E-mail address: alsesib@mail.ru, sryabinina@sfu-kras.ru,kumid@yandex.ru, slsadyrin@rambler.ru ORCID: 0000-0002-2432-1699 (Kudryavtsev); 0000-0001-9993-4118 (Kovalev)
} 
The proposed methods of selection and orientation towards specializations in physical education can be applied in universities regarding the practice of student sport as a reserve of high-performance sport and mass student sport. The proposed methods of orientation of students towards physical education specializations tailored to their individual characteristics can be applied in the system of higher physical education and in physical education classes at universities.

When assessing the conformity of the athlete's data to the chosen sport, which is a mathematical algorithm for assessing the conformity of professionally significant qualities to those required in the chosen sport, the obtained data on the athletes' conformity ranged from $70 \%$ to $93 \%$. These data confirm the previously obtained data on the prevailing tendencies in the severity of the typological characteristics of the nervous system properties in athletes doing different sports, as well as the correspondence of the typological complex of the nervous system of those under the study with the athletes' morphological and functional characteristics required in elite sports. As a result of the study, the established correspondence of these students to the chosen specializations ranges from $48 \%$ (rock climbing, 1 st year female students) to $87 \%$ (female students, basketball). The following motives can be considered the most significant for the group of students under the study: health preservation, social sphere, and physical perfection. The use of modern methods of orientation and selection in the context of the sportization of physical education will contribute to solving the problems that the staff of the Department of Physical Education face in helping the students to choose the type of physical activity (the student's orientation towards mass student sport, health-improving physical education), as well as a specific sport.

Keywords: sportization, student sport, physical education specialization, sports selection and orientation.

Research area: theory and methodology of physical education, sports training, healthimproving and adaptive physical culture: management in the physical culture system.

Citation: Kovalev, V.N., Ryabinina, S.K., Kudryavtsev, M.D., Sadyrin, S.L. (2021). Integrated technology of University students' sports selection and orientation in physical education specializations tailored to individual characteristics. J. Sib. Fed. Univ. Humanit. Soc. Sci., 14(2), 226-240. DOI: 10.17516/19971370-0714. 


\title{
Комплексная технология спортивного отбора и ориентации студентов вузов в учебные физкультурные специализации с учетом индивидуальных особенностей
}

\author{
В.Н. Ковалев ${ }^{\text {, С.К. Рябинина }}$, \\ М.Д. Кудрявцев ${ }^{a, 6, в}$, С.Л. Садырина \\ ${ }^{a}$ Сибирский федеральный университет \\ Российская Федерачия, Красноярск \\ ${ }^{6}$ Сибирский юридический институт МВД России \\ Российская Федерация, Красноярск \\ ${ }^{8}$ Сибирский государственный университет науки \\ и технологий имени М. Ф. Решетнева \\ Российская Федерация, Красноярск
}

\begin{tabular}{l}
\hline Аннотация. В статье выполнен анализ студенческого спорта, который является, \\
с одной стороны, резервом спорта высших достижений, с другой - мощным фактором \\
здоровьесбережения и социализации будущих специалистов и активных членов \\
общества. В статье рассмотрены спортивный отбор и ориентация в контексте \\
спортизации направленности занятий физической культурой в вузах с учетом \\
здоровьесбережения студентов, построение здоровьеформирующего образовательного \\
пространства, обеспечивающего освоение студентами здоровьеформирующих \\
ценностей и смыслов, позволяющих улучшать их здоровье и физические кондиции. \\
Целью исследования является разработка, применение и оценка результативности \\
комплексной технологии спортивного отбора и ориентации студентов вузов в учебные \\
физкультурные специализации с учетом индивидуальных особенностей.
\end{tabular} Общенаучная методология исследования представлена системным подходом к определению индивидуальных особенностей человека в единстве и взаимосвязи биологического, социального и психологического компонентов, их влияния на выбор и успешность в определенной деятельности, влиянии на здоровье. Применялись методы научного анализа, наблюдения, эксперимента, эмпирические, методы психологической диагностики, психофизиологические методы, статистические и математические методы. Исследование проводилось с января 2016 по сентябрь 2020 года. В исследовании приняли участие 327 человек: спортсмены ДЮСШОР Красноярского края, взрослые спортсмены и студенты 1-3 курсов различных институтов СФУ из учебных специализаций: баскетбол, аэробика, скалолазание.

Предложенные методы отбора и ориентации в учебные специализации по физической культуре могут применяться в вузах с учетом рассмотрения опыта студенческого спорта как резерва спорта высших достижений и массового студенческого спорта, а также в системе высшего физкультурного образования и на учебных занятиях по физической культуре в вузах.

При оценке соответствия данных спортсмена избранному виду спорта (ИВС), представляющей собой математический алгоритм оценки соответствия наличия профессионально значимых качеств к требуемым в избранном виде спорта, были получены данные о соответствии спортсменов в диапазоне 70-93 \%. Эти данные подтверждают ранее полученные данные о преобладающих тенденциях в выраженности типологических особенностей свойств нервной системы у представителей разных видов спорта, а также соответствие типологического комплекса нервной системы 
обследуемых и морфофункциональных особенностей спортсменов требуемым в спорте высших достижений. В результате исследования установлено соответствие данных студентов избранным специализациям от 48 (скалолазание, девушки, 1 курс) до 87 \% (девушки, баскетбол). Наиболее значимы для исследуемой группы студентов следующие мотивы: здоровьесбережение, социальная сфера и физическое совершенствование.

Применение современных методов ориентации и отбора в контексте спортизации физического воспитания будет способствовать решению задач, стоящих перед преподавателями кафедры физической культуры, в помощи студенту при выборе вида физической активности (ориентации студента на занятия массовым студенческим спортом, оздоровительную физическую культуру), а также определенного вида спорта.

Ключевые слова: спортизация, студенческий спорт, физкультурная учебная специализация, спортивный отбор и ориентация.

Научная специальность: 13.00.04 - теория и методика физического воспитания, спортивной тренировки, оздоровительной и адаптивной физической культуры.

\section{Введение}

Развитие студенческого спорта является значимым фактором для формирования резерва спорта высших достижений и для создания культуры ценностей здорового образа жизни в студенческой среде (Perspektivy razvitiya sovremennogo...). С другой стороны, тенденция интенсификации учебного процесса в вузах с целью повышения качества и уровня готовности к профессиональной деятельности диктует необходимость повышения мер по сохранению здоровья студентов (Shevyrdyayeva, Lygina, 2017). В вузах задача психофизической адаптации студента, оказывающей значительное влияние на состояние здоровья, ложится на плечи дисциплины «Физическая культура». Отмечено, что обычно на младших курсах реализуется адаптация к обучению в вузе, а на старших - к будущей профессиональной деятельности (Lozovaya, Lozovoy). Учитывая распространение концепции спортизации занятий физической культурой в высшей школе вполне логичен подход, в котором при проектировании развития студенческого спорта учитывается, что он, как и современный спорт в целом, может быть подразделен (а на взгляд авторов статьи, должен быть подразделен) на массовый и спорт высших достижений с присущими каждому из них целями и задачами (Peshkova, Lubysheva,
Peshkov). Под спортизацией физического воспитания в настоящее время понимается активное использование спортивной деятельности, спортивных технологий, соревнований и элементов спорта в образовательном процессе с целью формирования спортивной культуры обучающихся (Lubysheva, 2017). Говоря о студенческом спорте массовом, высших достижений и занятиях физической культурой в учебных группах различных специализаций, в контексте спортизации, на наш взгляд, необходимо более детально рассмотреть вопросы спортивного отбора и ориентации. Следует учитывать при этом, что, с одной стороны, спорт является специфической частью физической культуры, с другой - физическая культура есть базисная основа спорта как в отношении ознакомления с физическими упражнениями и тренировочными воздействиями, так и в отношении выявления будущих спортсменов, обладающих потенциалом для высоких спортивных достижений, а также цели и задачи студенческого спорта и физического воспитания в вузе.

Если целью физической культуры, как известно, служит оптимизация физического развития человека, всестороннего совершенствования свойственных каждому физических качеств и связанных с ними способностей в единстве с воспитанием духовных и нравственных качеств, ха- 
рактеризующих общественно активную личность, обеспечивая на этой основе подготовленность каждого члена общества к плодотворной трудовой и другим видам деятельности (Goloshchapov, 2001), то цель спортивной подготовки (в спорте высших достижений) - достижение максимально возможного для данного индивидуума уровня технико-тактической, физической и психической подготовленности, обусловленного спецификой вида спорта и требованиями достижения максимально высоких результатов в соревновательной деятельности.

Задачи массового спорта, во многом повторяя задачи физической культуры, реализуются спортивной направленностью регулярных занятий и тренировок. Цели занятий различными видами массового спорта - укрепление здоровья и улучшение физического развития, подготовленность и активный отдых. Это связано с решением таких частных задач, как повышение функциональных возможностей отдельных систем организма, коррекция физического развития и телосложения, повышение общей и профессиональной работоспособности, овладение жизненно необходимыми умениями и навыками, досуг и достижение физического совершенства.

Большинство исследователей согласны с мнением Н.В. Авековича, Б. А. Ашмарина, С. М. Вайцеховского, М. И. Цейтина в том, что ядро спорта состоит из трех элементов: спортивного отбора, тренировки и соревнования, обоснованно считая, что эти три элемента - та основа, через которую проявляются функционирование и развитие сферы спорта в целом. И не случайно спортивный отбор стоит первым в этой триаде. Его задача - отбор наиболее пригодных к конкретному виду спорта. Ведь если речь заходит о высоких спортивных достижениях, отмечает Е.П. Ильин, необходимо иметь природную предрасположенность к тому или иному занятию (а не только трудолюбие, которым можно добиться многого, но не всего). Именно это и подразумевается, когда речь идет о спортивной пригодности (Il'in, 2016). Трени- ровочные воздействия, направленные на развитие способностей и последующее проявление их в соревнованиях, напрямую зависят от спортивного отбора.

На разных этапах многолетней спортивной подготовки цели и задачи отбора меняются от отбора здоровых, хорошо координированных детей и подростков (этап начальной подготовки) до отбора в сборные команды страны для участия в соревнованиях мирового и международного уровней (этап высшего спортивного мастерства), где основной формой отбора служат спортивные соревнования, их динамика, соответствие основных компонентов физической подготовленности и физического развития требованиям конкретного вида спорта на уровне результатов мастера спорта международного класса. Определенно сложившиеся формы и методы спортивного отбора по-прежнему актуальны как для современного, так и для студенческого спорта как резерва спорта высших достижений.

Если рассматривать ядро деятельности как связь системообразующих элементов, то, учитывая основные принципы физического воспитания, ее ядром можно считать оздоровительную направленность (следовательно, общедоступность), всестороннее гармоничное развитие личности (согласованное и соразмерное развитие физических способностей, формирование разносторонних двигательных умений и навыков и освоение специальных знаний, связь с другими видами воспитания), связь с практической общественно значимой деятельностью (нацеленность на первоочередное формирование жизненно важных двигательных умений и навыков, формирование способностей действовать полезно и эффективно в условиях трудовой и военной деятельности). То есть логично, на наш взгляд, считать ядром физического воспитания общедоступность, оздоровительную направленность применяемых физических упражнений и общественно-практическую направленность полученных знаний, умений и навыков. Безусловно, при рассмотрении физкультурной деятельности и занятий физической культурой, в частности, речь 
может идти только об ориентации и на здоровый образ жизни, и на формирование гармонично развитой личности и т. д.

Будучи компонентами (формами) физической культуры, спорт и физическое воспитание имеют общие цели, направленные на формирование личности, здоровьесбережение и, как следствие, повышение качества и продолжительности активной жизни человека.

Целью исследования является разработка, применение и оценка результативности комплексной технологии спортивного отбора и ориентации студентов вузов в учебные физкультурные специализации с учетом индивидуальных особенностей.

\section{Постановка проблемы исследования}

Таким образом, учитывая различия в целях и задачах студенческого спорта высших достижений (а также рассмотрение его как резерва спорта высших достижений), массового студенческого спорта и занятий в физкультурных учебных группах, необходимо решить проблему спортивного отбора и ориентации на выбор определенной учебной специализации студенческой молодежью. Этим каждому студенту вуза обеспечиваются возможности для занятий физкультурно-спортивной деятельностью, наиболее соответствующей его индивидуальным особенностям и направленности личности, и ориентация наиболее раннего включения его в участие в спортивномассовых и физкультурно-спортивных мероприятиях. При решении проблемы необходимо учитывать следующее:

1. Специфика занятий физкультурноспортивной деятельностью, материальнотехническое обеспечения, кадровый состав вузов.

2. Цели и задачи студенческого спорта и физического воспитания в вузе, спортивные традиции.

3. Спортизация предполагает конверсию технологий спортивной тренировки с целью управления процессом индивидуального психофизического развития человека на основе адекватной задачам физического воспитания модификации систем спортивных упражнений, принципов и методов их применения.

4. Проблема спортивной ориентации и отбора в настоящее время не находится в стадии становления, а интегрировала в самостоятельно развивающуюся науку. В основном разрабатываются системы спортивного отбора и ориентации для выявления одаренных детей и подростков. Специалисты оснащены методами отбора и аппаратно-программными диагностическими комплексами.

5. В студенческом (старшем юношеском) возрасте происходит завершение физического созревания человека, бурного роста его самосознания, профессионального самоопределения, самооценки. В этот период времени складывается определенная жизненная позиция, происходит интенсивное формирование ценностных ориентаций, оказывающих влияние на становление характера и здоровья личности в целом, что значительно упрощает применение методов спортивного отбора и ориентации, основанных на оценке соответствия данных студента к требуемым в определенном виде физической активности либо избранном виде спорта, а также выявления перспективных зон развития действующего спортсмена.

Решение данной проблемы возможно, на наш взгляд, при разработке и применении комплексной технологии спортивного отбора и ориентации студентов вузов на учебные физкультурные специализации с учетом индивидуальных особенностей (далее технология). То есть необходимо создать условия, разработать методику для отбора студенческой молодежи, способной и ориентированной на достижение высоких спортивных результатов, на массовый студенческий спорт и активные занятия в учебных физкультурных группах. Это соответствует «Стратегии развития физической культуры и спорта в Российской Федерации до 2030 года», где первой задачей обозначено формирование среды равных возможностей для занятий физической культурой и спортом с учетом индивидуальных потребностей граждан и содействие повышению качества жизни всех категорий 
и групп населения, а одним из приоритетных направлений является повышения роли физической культуры и спорта в системе образования (Proyekt «Strategii razvitiya fizicheskoy...).

Применение современных методов ориентации и отбора в контексте спортизации физического воспитания будет способствовать решению задач, стоящих перед преподавателями кафедры физической культуры в помощи студенту при выборе вида физической активности (ориентации студента на занятия массовым студенческим спортом, оздоровительной физической культуры), а также определенного вида спорта. Следует учесть, что говоря о рассмотрении пригодности с психологических позиций (пригодность рассматривается на трех уровнях: нейродинамическом, психических процессов и личной направленности), видный ученый Е.П Ильин отмечает: для надежности прогноза об одаренности и пригодности своих учеников тренер должен опираться на научно обоснованные критерии и методики. Для объективности отбора должны привлекаться разные специалисты, в том числе и психологи, владеющие инструментальными методами выявления способностей и обуславливающих их задатков (Il'in, 2016).

В студенческом спорте высших достижений, как отмечено выше, имеющем свои цели и задачи, спортивный отбор как комплекс мероприятий по выявлению спортсменов, обладающих высоким уровнем способностей, отвечающих требованиям специфики вида спорта, так же актуален, как и в современном спорте в целом.

\section{Концептологические}

\section{основания исследования}

1. Идея спортизации В.К. Бальсевича, предложившего в конце прошлого века конверсию основных положений теории спортивной подготовки в процесс физического воспитания детей и студенческой молодежи с целью управления процессом индивидуального психофизического развития на основе адекватной задачам физического воспитания модификации систем спортив- ных упражнений, принципов и методов их применения. В настоящее время под спортизацией понимается активное использование спортивной деятельности, спортивных технологий, соревнований и элементов спорта в образовательном процессе с целью формирования спортивной культуры обучающихся (Lubysheva, 2017).

2. Теория Н.А. Бернштейна о «живых движениях», его идеи об активности и реактивности в действиях человека, понятие ученого о двигательной задаче, отраженное им в монографии «О построении движений возникающих перед организмом двигательных задачах» (Bernshteyn, 1990). Теория о «живых движениях» получила продолжение в исследованиях В.К. Бальсевича и отражена им в фундаментальном труде «Онтокинезиология человека» (Bal'sevich, 2000), где автором представлена концепция возрастной эволюции кинезиологического потенциала человека (от рождения до старости), определены этапы, формы, средства и методы его естественного и стимулируемого развития в зависимости от особенностей индивидуального психофизического состояния (Lubysheva, 2017).

3. Идеи и концепция построения живых движений как социокультурного объекта на основе системно-структурного подхода Д. Д. Донского (Donskoy, 1971; Donskoy, Dmitriyev, 1993).

4. Деятельностная теория личности Л.С. Рубинштейна и рассмотрения им мотивации как ядра личности.

5. Современные подходы к спортивному отбору и ориентации.

6. Теоретико-методологическое и экспериментальное обоснование инновационного направления модернизации физкультурно-спортивной практики в системе образования как спортизации физического воспитания детей и молодежи Л.И. Лубышевой (Lubysheva, 2017).

\section{Методология, организация, материал и методы исследования}

Общенаучная методология исследования представлена системным подходом к определению индивидуальных особен- 
ностей человека в единстве и взаимосвязи биологического, социального и психологического компонентов, их влияния на выбор и успешность в определенной деятельности, влиянии на здоровье. Применялись методы научного анализа, наблюдения, эксперимента, эмпирические, статистические и математические методы.

Частными методами исследования являются:

1) изучение и анализ научной литературы по вопросам спортизации, спортивного отбора и ориентации, индивидуальных особенностей человека и методов их исследования, биомеханики, математического анализа;

2) методы психофизиологической диагностики, направленные на выявление индивидуальных особенностей протекания нервных и психических процессов, выявление типологического комплекса нервной системы;

3) методы психологической диагностики, направленные на определение индивидуальных психологических свойств, особенностей психических состояний, и психических процессов;

4) методы исследования морфологических и функциональных данных, направленные на определение особенностей и состояний кардиореспираторной системы и соматометрических показателей;

5) математический метод оценки соответствия данных к требуемым в определенном виде физической активности.

Исследование проводили с января 2016 по сентябрь 2020 года. В исследовании приняли участие 30 спортсменов ДЮСШОР Красноярского края, юноши и девушки в возрасте 12-14 лет; 10 спортсменов спорта высших достижений (2 мастера спорта международного класса, 8 мастеров спорта и кандидатов в мастера спорта), возрастная группа 18-27 лет; студенты 1-3 курсов различных институтов СФУ из учебных специализаций: баскетбол, аэробика, скалолазание, всего 287 студентов, юношей и девушек в возрасте 17-22 лет. Таким образом, в исследовании приняли участие 327 человека.

\section{Этапы исследования}

Исследование проводили в три этапа:

На первом этапе (2016-2018 годы) была изучена научная литература по вопросам отбора и ориентации, спортизации. Определены методы установки эталонных характеристик спортсменов, профили профессионально значимых свойств и качеств, а также сформированы пакеты диагностических методик по их выявлению (2016 год, январь - март). На основании диагностики на предрасположенность к определенному виду спорта была сформирована группа спортсменов вида спорта лыжные гонки 1-2-го года тренировочного этапа спортивной подготовки, 2016 год, март - апрель, после чего осуществлялись диагностические мероприятия в рамках сопровождения отобранных спортсменов, исследованы данные десяти спортсменов членов сборной Края и России по виду спорта лыжные гонки.

На втором этапе (2018-2020 годы) разрабатывалась технология отбора и ориентации, проводилась диагностика студентов СФУ для оценки их предрасположенности к определенному виду физической активности (сентябрь 2019 - февраль 2020). Продолжались диагностические мероприятия по контролю развития профессионально значимых характеристик спортсменов лыжных гонок, их спортивных достижений (2016 - август 2019).

На третьем этапе исследования (февраль 2020 - сентябрь 2020) было сформировано учебно-методическое пособие по технологии отбора, проведен анализ полученных данных, студентам СФУ даны рекомендации по определенным видам физической активности.

\section{Традиции}

Спорт - один из приоритетов Сибирского федерального университета (СФУ), его студенты неоднократно становились чемпионами и призерами Всероссийской зимней и летней Универсиад, победителями всероссийских и европейских соревнований, чемпионами мира среди студентов. Развиты различные виды спора - биатлон, лыжные гонки, горные лыжи, сноуборд, 
и летние - женский футбол, мужской мини-футбол, пеший туризм, бокс, вольная и греко-римская борьба. Министерство науки и высшего образования, Министерство спорта и Российский спортивный студенческий союз (РССС) уже пять лет проводят конкурс «Звезды студенческого спорта». Следует отметить, что продолжающая российские студенческие традиции XXIX зимняя Универсиада, где сборная страны завоевала рекордное количество медалей 112 , по мнению участников и гостей, стала самой яркой в истории студенческих игр. Студенты СФУ принимали в ней участие не только как участники соревнований, значительная часть волонтеров состояла из студентов нашего университета. Студенты Сибирского федерального университета получили 12 медалей (5 золотых, 4 серебряных и 3 бронзовых) на Всемирной зимней универсиаде по 5 видам спорта. Это вывело красноярский вуз на второе место в медальном зачете среди всех 220 вузов-участников из 58 стран. В СФУ активно функционирует спортивный клуб, формируются сборные команды институтов по различным видам спорта, а также сборная команда университета.

\section{Условия}

Образовательный процесс по физическому воспитанию в СФУ реализуется преподавателями кафедры физической культуры Института физической культуры спорта и туризма (ИФКСиТ) в различных учебных физкультурных группах. Преподаватели имеют спортивный опыт (спортсменов и судей). При кафедре физической культуры осуществляет деятельность лаборатория функциональной и двигательной деятельности человека (ФиДДЧ). Деятельность лаборатории ФиДДЧ определяется как прикладная научно-исследовательская по регистрации, анализу и прогнозу состояния социального, общего, физического и психического компонентов здоровья студентов, их взаимосвязи с учебным процессом, а также прогнозу перспектив адаптации молодых специалистов в избранной профессии.
Основные направления деятельности:

1. Формирование индивидуальной здоровьесберегающей среды студента - мониторинг здоровья студентов.

2. Повышение результативности и практической значимости научноисследовательских работ научнопедагогических кадров вуза, направленных на оптимизацию учебного процесса.

3. Исследования по определению влияния индивидуальных особенностей студента на образовательный процесс.

4. Вопросы спортизации занятий физической культурой.

Проводятся исследования, позволяющие получить:

1) антропологические и функциональные данные для оценок состояний и функционирования сердечно-сосудистой и дыхательной систем. Эти данные обрабатываются по программе «АСУ Здоровье» и оформляются в форме «Паспорта здоровья», позволяют отслеживать динамику физического развития студента в течение 3 лет;

2) данные о типологическом комплексе нервной системы, мотивационной сферы и других психофизиологических и психологических актуальных характеристик студентов.

В СФУ активно функционирует спортивный клуб. Формируются сборные команды институтов по различным видам спорта, а также сборная команда Университета.

\section{Описание технологии}

\section{«Комплексная технология}

спортивного отбора и ориентации

студентов вузов в учебные

физкультурные специализации

с учетом индивидуальных особенностей»

Технология относится к многомерным технологиям спортивного отбора и ориентации.

Основу технологии составляет метод обобщения независимых характеристик с личностным подходом, что обеспечено рассмотрением индивидуальных особенно- 
стей студента как оптимального развития профессионально значимых качеств к генетически заданным возможностям студента. Обобщение осуществляется на основе диагностики с применением аппаратнопрограммных комплексов и методики оценки соответствия профессионально значимых качеств, выявленных у студента, требуемых в избранном виде физкультурно-спортивной деятельности.

Системообразующими элементами технологии являются:

- метод определения профессионально значимых качеств, необходимых в конкретном виде спорта, как описание/составление модели спортсмена международного класса;

- диагностическая методика определения наличия у студента (спортсмена) профессионально значимых свойств и качеств с применением аппаратно-программных комплексов, представляющая собой применение сформированного пакета диагностических методов (психофизиологических, психологических, медицинских, педагогических);

- метод оценки соответствия данных спортсмена избранному виду спорта либо учебной специализации, представляющий собой математический алгоритм оценки соответствия наличию профессионально значимых качеств, требуемых в избранном виде спорта.

\section{Технологические этапы исследования}

1. Сбор первичной информации о студенте. Проводится методом анкетирования, тестирования для получения сведений опредшествующем физкультурноспортивном опыте студента, сформированности физкультурно-спортивной направленности личности, мотива достижения и склонности к риску. Также на этом этапе определяется психологический пол студента, который, как и биологический, влияет на выбор вида физкультурно-спортивной деятельности и успешности в ней.

2. Применение метода определения профессионально значимых качеств, необходимых в определенном виде спорта, как описание/составление модели спортсмена международного класса.

3. Применение методики определения наличия у спортсмена профессионально значимых свойств и качеств личности путем применения сформированного пакета диагностических аппаратных методов.

4. Соответствие уровня данных спортсмена избранному виду спорта либо учебной специализации.

5. Составление и передача рекомендаций студенту о предпочтительном для него виде специализации (в форме консультирования).

\section{Диагностические методики, применяемые в технологии}

Психофизиологические методы:

1. Экспресс-методика «Теппинг-тест» применяется для диагностирования силы нервных процессов путем измерения динамики темпа движений кисти. Сила нервных процессов отражает общую работоспособность человека. Выявляемые типы нервной системы по критерию силы: слабая, средняя, сильная.

2. Динамометрия - оценка подвижности нервных процессов. Теоретической основой данной методики служит психофизиологическая закономерность, отражающая сущность подвижности нервных процессов и заключающаяся в том, что нервный процесс возбуждения или торможения, возникнув, не исчезает сразу, а ослабевает постепенно. Наличие следов одного нервного процесса препятствует развитию противоположного процесса.

3. Методика «Реакция на движущийся объект» предназначена для измерения уравновешенности нервных процессов, т. е. степени сбалансированности процессов возбуждения и торможения по силе, представляет собой разновидность сложной сенсомоторной реакции, т. е. такой реакции, которая помимо сенсорного и моторного периодов включает период относительно сложной обработки сенсорного сигнала центральной нервной системой. Выявляемые типы нервной системы по критерию «уравновешенность»: уравновешенность нервных 
процессов, неуравновешенность нервных процессов с преобладанием силы возбуждения, неуравновешенность нервных процессов с преобладанием силы торможения.

4. Методика «Простая зрительно-моторная реакция». Определяются показатели: низкий, средний, высокий. Простая зрительно-моторная реакция (ПЗМР) - это элементарный вид произвольной реакции человека на зрительный стимул.

Морфофункциональные методы исследования:

1. Первичным этапом изучения морфологических особенностей спортсменов является определение тотальных размеров тела, которые делят на пространственные и весовые. К первым относятся линейные размеры, объемные и поверхностные. Ко вторым - масса тела (вес в кг). Определяемые параметры: рост, вес, жизненная емкость легких, окружность грудной клетки.

Методы диагностики состояний и функционирования сердечно-сосудистой и дыхательной систем. По результатам полученных данных рассчитывают антропометрические и функциональные индексы. Для вывода объективной оценки уровня физического состояния учитываются общая и специальная физическая подготовленности.

Методы психологической диагностики:

1. Методика «Оценка внимания» предназначена для диагностики концентрации и устойчивости внимания.

2. Методика «Красно-черные таблицы Шульте-Платонова» предназначена для изучения объема, переключаемости и распределения внимания.

3. Методика диагностики личности на мотивацию к успеху Т. Элерса. Личностный опросник. Предназначен для диагностики, выделенной Хекхаузеном, мотивационной направленности личности на достижение успеха. Результат теста «Мотивация к успеху» анализировали вместе с результатами тестов «Мотивация к избеганию неудач», «Готовность к риску».

4. Методика диагностики личности на мотивацию к избеганию неудач Т. Элерса. Личностный опросник. Предназначен для диагностики, выделенной Хекхаузеном, мотивационной направленности личности на избегание неудач. Методика диагностики степени готовности к риску Шуберта. Методика оценивает особенности поведенческих реакций человека в ситуациях, сопряженных с неопределенностью, опасностью для жизни.

5. Методика «Изучение мотивов занятий спортом» (применялась к спортсменам). Методика разработана В.И. Тропниковым для выяснения степени важности различных причин (ситуаций, обстоятельства), которые побудили и побуждают спортсмена продолжать заниматься выбранным им видом спорта.

6. Личностный опросник Кеттела. Предназначен для описания широкой сферы индивидуально-личностных отношений. Отличительная черта данного опросника его ориентация на выявление относительно независимых 16 факторов (шкал, первичных черт) личности.

7. Индивидуально-типологический опросник (ИТО) (для возраста 14 лет применяли при диагностике спортсменов лыжных гонок). С помощью ИТО определяют типологические особенности индивида, ведущие черты его характера. Кроме того, он способствует выявлению спектра наиболее подходящих каждому конкретному обследуемому лицу видов профессиональной деятельности и преобладающих деловых качеств. По результатам обследования легко понять, насколько уравновешен индивид, какие особенности его характера акцентуированы, в благоприятной ситуации ли он находится или дезадаптирован.

8. Определение вида контроля моторной координации «Проба Ромберга». Вид контроля моторной координации испытуемого исследуется путем применения пробы Ромберга на стабилометрической платформе $\mathrm{S}-150$.

\section{Результаты и их обсуждение}

Диагностика спортсменов лыжных гонок проводилась в медицинских кабинетах спортивных школ.

Мероприятие состояло из трех фаз: 
1. Проведение совещания с администрацией школы с участием инструкторовметодистов и тренерского состава. На совещаниях были обозначены цели и задачи исследования - спортивный отбор и ориентация спортсменов, имеющих задатки к достижению высоких спортивных результатов, внутривидовая (предпочтительные дистанции) и родственная ориентации (в родственные виды спорта). Составляли план проведения мероприятий с учетом «календаря» спортсменов, задействованных в эксперименте, сроки передачи отчетов о полученных данных, консультирование, формировали документальную базу с обязательным оформлением согласия на обработку персональных данных.

2. Проведение диагностических мероприятий. Акцент был сделан на условия проведения диагностики (изолированные помещения, освещение и т. д.), исключение «ожидания» спортсменом начала диагностики, так как спортсмен должен находиться в спокойном состоянии. Исследование проводилось тремя специалистами однойтремя пробами в зависимости от вида диагностики, в разное время суток.

3. Передача отчетов и рекомендаций тренерам и администрации в двух разных формах.

\section{Результаты диагностики}

представителей спорта высших достижений

Выявлено, что по параметру силы нервной системы обследованные спортсмены вида спорта лыжные гонки имеют нервную систему слабой силы (слабая нервная система) - 10 человек; уравновешенность возбуждения и торможения по внешнему и внутреннему балансу 10 человек; инертность возбуждения и торможения 6 человек.

При исследовании морфофункциональных особенностей данной группы установлено: жизненная емкость легких (ЖЕЛ) у исследуемых спортсменов находится в пределах 5500-7000 мл, что является большой величиной, свойственной лыжникам-олимпийцам.

Средний рост лыжников, участвующих в олимпиадах, составляет 178 см, а лыжниц -170 см. В данной группе рост спортсменов мужчин 177-181, спортсменок 168-172 см. Средняя лыжница - участница Олимпийских игр весит 64 кг, а средний мужчина-олимпиец - 75 кг. Весовые параметры исследуемой группы соответствуют показателям олимпийцев: мужчины 7177 кг, женщины 61-66 кг.

Также следует отметить удлиненность бедра по отношению к голени от 1 до 2 см у спортсменов данной группы, что соответствует данным, полученным другими исследователями.

Bce это подтверждает ранее полученные данные о преобладающих тенденциях в выраженности типологических особенностей свойств нервной системы у представителей разных видов спорта, a также соответствие типологического комплекса нервной системы обследуемых и морфофункциональных особенностей спортсменов, требуемых в спорте высших достижений.

\section{Результаты диагностики спортсменов ДЮСШОР по виду спорта лыжные гонки высших достижений}

Таким образом, по полученной модели спортсменов международного уровня была сформирована группа спортсменов: 30 человек - 17 юношей и 13 девушек.

При отборе учитывалось: 1) мнение о том, что одним из основных направлений ранней спортивной ориентации должно стать определение «доминирующего типа соответствия» (морфологического, функционального, биомеханического, психомоторного) ребенка выбранному виду спорта (Guba). Рассматривали типологический комплекс нервной системы, жизненный объем легких, весоростовые показатели, конституционные особенности.

При оценке соответствия данных спортсмена избранному виду спорта (ИВС), представляющей собой математический алгоритм оценки соответствия наличия профессионально значимых качеств к требуемым в избранном виде спорта, были получены данные о соответствии спортсменов в диапазоне 70-93 \% (табл. 1). 
Victor N. Kovalev, Svetlana K. Ryabinina... Integrated Technology of University Students' Sports Selection...

Таблица 1. Выявленные показатели по каждому профилю

Table 1. Identified indicators for each profile

\begin{tabular}{|c|c|c|}
\hline Наименование профиля & $\begin{array}{c}\text { Показатель максимального } \\
\text { соответствия профилю (ПМСП) }\end{array}$ & $\begin{array}{c}\text { Выявленный показатель } \\
\text { по профилю (ВПП) }\end{array}$ \\
\hline Психофизиологический & Макс $=20$ & 14 \\
\hline Морфотипологический & Макс $=20$ & 17 \\
\hline Психологический & Макс $=20$ & 12 \\
\hline Функциональный & Макс $=20$ & 56 \\
\hline Итого & 80 & 13 \\
\hline
\end{tabular}

Оценка соответствия наличия профессионально значимых качеств вычисляется как сумма выявленных показателей каждого профиля.

В процентном соотношении оценка соответствия наличия профессионально значимых качеств (ОСПЗК - оценка соответствия наличия профессионально значимых качеств) вычисляется по формуле

$$
\frac{100}{\Pi М С п} \times \text { ВПП }=\text { ОСПЗК. }
$$

Для данного примера значение ОСПЗК составило $70 \%$.

В период март 2016 - январь 2018 года осуществляли диагностические мероприятия в рамках сопровождения отобранных спортсменов. В настоящее время 12 человек из данной группы входят в состав сборной команды края, являются победителями и призерами всероссийских соревнований.

\section{Результаты диагностики студентов учебных физкультурных специализаций институтов СФУ}

Исследование проводили в лаборатории ФиДДЧ в спортивном комплексе с плавательным бассейном в городе Красноярске (ул. Академика Киренского д. 15). В исследовании приняли участие 287 студентов институтов СФУ физкультурных учебных специализаций - баскетбол, аэробика, скалолазание. Цель исследования - оценка уровня соответствия студентов избранным специализациям.

Студенты групп приходили на обследования по заранее составленному расписа-

Таблица 2. Результаты исследований индивидуальных особенностей студентов и их соответствия избранной специализации

Table 2. Research results of individual characteristics of students and their correspondence to the chosen specialization

\begin{tabular}{|c|c|c|c|c|c|c|}
\hline Курс & Пол & $\begin{array}{l}\text { Специализация } \\
\text { по физкультуре }\end{array}$ & $\begin{array}{l}\text { Кол-во } \\
\text { человек }\end{array}$ & $\begin{array}{l}\text { Морфофунк- } \\
\text { циональные } \\
\text { особенности }\end{array}$ & $\begin{array}{c}\text { Психофизиологиче- } \\
\text { ские особенности }\end{array}$ & $\begin{array}{c}\text { Уровень } \\
\text { соответствия, } \%\end{array}$ \\
\hline I & ж & аэробика & 80 & 80 & 80 & $49-63$ \\
\hline II & ж & аэробика & 40 & 40 & 40 & $57-70$ \\
\hline III & ж & аэробика & 23 & 23 & 23 & $60-82$ \\
\hline I & ж & скалолазание & 14 & 14 & 14 & $48-67$ \\
\hline II & ж & скалолазание & 7 & 7 & 7 & $50-70$ \\
\hline I & ж & б/б & 17 & 17 & 17 & $60-87$ \\
\hline I & $\mathrm{M}$ & б/б & 74 & 74 & 74 & $64-85$ \\
\hline I & M & скалолазание & 36 & 36 & 36 & $50-70$ \\
\hline Всего & & & 287 & 287 & 287 & $48-87$ \\
\hline
\end{tabular}


нию. Исследование проводили три специалиста с 8 до 16 часов.

Следует отметить, что студенты проявляли заинтересованность в исследовании, что выражалось с их стороны в уточняющих вопросах как в ходе исследования, так и при передаче заключений.

Преподаватели демонстрировали большую заинтересованность в получении информации о здоровье студентов. Что, безусловно, говорит о здоровьесберегающей направленности проводимых ими занятий. Ряд преподавателей предложил исследовать коммуникабельность, мотивационную сферу и лидерские качества студентов, что можно, на наш взгляд, считать заинтересованностью преподавателей в социализации студентов.

В результате исследования соответствие данных студентов избранным специализациям от 48 \% (скалолазание, девушки, 1 курс) до 87 \% (баскетбол, девушки).

Следует отметить, что уровни соответствия повышаются от первых курсов к третьим, что, с одной стороны, может являться показателем развития некоторых способностей, с другой - показателем отсева студентов, не обладающих необходимыми данными, а также переход их в другие специализации. Самый высокий уровень соответствия выявлен в специализации баскетбол. Что, по нашему мнению, может быть объяснено ростовыми параметрами вида спорта и их учета преподавателями при ориентации студентов в специализации.

\section{Выводы}

1. Применение современных методов ориентации и отбора в контексте спортизации физического воспитания будет способствовать решению задач, стоящих перед преподавателями кафедры физической культуры, в помощь студенту при выборе вида физической активности (ориентации студента на занятия массовым студенче- ским спортом, оздоровительную физическую культуру), а также определенного вида спорта.

2. Современные методы спортивного отбора и спортивная ориентация могут быть применены в физкультурно-спортивной деятельности студентов.

3. В отношении студенчества более корректным будет понятие «подбор определенного вида спорта на основании соответствия индивидуальных особенностей студента определенному уровню физического развития и физической подготовленности и его интересам». Технологии по отбору и ориентации в высшей школе в контексте спортизации необходимо разрабатывать и применять с учетом технической базы и кадрового обеспечения конкретного вуза. Также необходимо учитывать спортивные традиции.

4. При оценке соответствия данных спортсмена избранному виду спорта (ИВС), представляющей собой математический алгоритм оценки соответствия наличия профессионально значимых качеств, требуемых в избранном виде спорта, были получены данные о соответствии спортсменов в диапазоне 70-93 \%. Они подтверждают ранее полученные данные о преобладающих тенденциях в выраженности типологических особенностей свойств нервной системы у представителей разных видов спорта, а также соответствие типологического комплекса нервной системы обследуемых и морфофункциональных особенностей спортсменов, требуемых в спорте высших достижений.

5. В результате исследования установлено соответствие данных студентов избранным специализациям от $48 \%$ (скалолазание, девушки 1 курс) до 87 \% (девушки, баскетбол). Наиболее значимые для исследуемой группы студентов мотивы: здоровьесбережение, социальная сфера и физическое совершенствование. 


\section{Список литературы / References}

Bal'sevich, V.K. (2000). Ontokineziologiya cheloveka [Human Ontokinesiology]. Moscow: Theory and practice of physical culture. $275 \mathrm{p}$.

Bernshteyn, N.A. (1990). O postroyenii dvizheniy [On the construction of movements]. Available at: http://elib.gnpbu.ru/text/bernshteyn_fiziologiya-dvizheniy_1990/(21.10.2020)

Goloshchapov, B.R. (2001). Istoriya fizicheskoy kul'tury i sporta: Ucheb. posobiye dlya studentov vuzov, obuch. po spetsial'nosti 033100 - fizicheskaya kul'tura [History of physical culture and sports: Textbook. manual for university students, studying specialty 033100 - physical education]. Moscow: Academy. $309 \mathrm{p}$.

Guba, V.P. Aktual'nyye problemy sovremennoy teorii i metodiki opredeleniya rannego sportivnogo talanta [Actual problems of modern theory and methodology for determining early sports talent]. Trener. Available at: http://lib.sportedu.ru/Press/TPFK/2000N9/p28-31.htm (18.10.2020)

Donskoy, D.D. (1971). Biomekhanika s osnovami sportivnoy tekhniki [Biomechanics with the basics of sports technology]. Moscow: Fizkul'tura i sport (FiS) [Physical education and sports]. 288 p.

Donskoy, D.D., Dmitriyev, S.V. (1993). Osnovy antropotsentricheskoy biomekhaniki (metodologi$y$ a, teoriya, praktika) [Fundamentals of anthropocentric biomechanics (methodology, theory, practice)]. Monograph. Nizhny Novgorod. $150 \mathrm{p}$.

Il'in, Ye.P. (2016). Psikhologiya sporta [Sports psychology]. SPb.: Piter. 352 p.

Lozovaya M.A., Lozovoy V.A. Voprosy sportizatsii v sotsiumakh. Sport dlya vsekh [Sportization issues in societies. Sports for all]. Available at: http://oreluniver.ru/file/science/confs/2015/sport/publ/5 Lozovaya Sport dlya vseh.pdf (17.10.2020)

Lubysheva, L.I., Zagrevskaya, A.I., Peredel'skiy, A.A., Manzheley, I.V., Litvinenko, S.N., Cherepov, Ye.A., Peshkova, N.V., Rodionova, M.A., Polivayev, A.G., Kondrat'yev, A.N., Bazilevich, M.V. (2017). Sportizatsiya $v$ sisteme fizicheskogo vospitaniya: ot nauchnoy idei $k$ innovatsionnoy praktike: monografiya [Sportization in the system of physical education: from a scientific idea to innovative practice: monograph]. Moscow: Research Center "Theory and Practice of Physical Culture and Sports". 200 p.

Perspektivy razvitiya sovremennogo studencheskogo sporta: na puti $k$ Universiade-2013 v Kazani: materialy Vserossiyskoy nauchno-prakticheskoy konferentsii (7-8 noyabrya 2012) [Prospects for the development of modern student sports: on the way to the 2013 Universiade in Kazan: materials of the All-Russian scientific and practical conference (November 7-8, 2012)] (2012). Kazan: Volga Region State Academy of Physical Culture, Sport and Tourism. 356 p.

Peshkova, N.V., Lubysheva, L.I., Peshkov, A.A. Surgutskiy gosudarstvennyy universitet, Surgut [Surgut State University, Surgut]. Available at: http://naukarus.com/sportizatsiya-fizicheskogo-vospitaniya-kak-uslovie-razvitiya-studencheskogo-sporta-v-vuzah-nesportivnogo-profilya (20.10.2020)

Proyekt «Strategii razvitiya fizicheskoy kul'tury i sporta do 2030 goda» [The project "Strategy for the development of physical culture and sports until 2030"]. Available at: https://minsport.gov.ru/activities/ proekt-strategii-2030/ (21.10.2020)

Shevyrdyayeva, K.S., Lygina, M.A. (2017). Izucheniye oriyentatsii studentov na vedeniye zdorovogo obraza zhizni i sformirovannosti tsennostnogo otnosheniya studentov $k$ zdorov'yu [Studying the orientation of students towards maintaining a healthy lifestyle and the formation of the value attitude of students to health]. Available at: https://cyberleninka.ru/article/n/izuchenie-orientatsii-studentov-na-vedenie-zdorovogo-obraza-zhizni-i-sformirovannosti-tsennostnogo-otnosheniya-studentov-k-zdorovyu (22.10.2020) 